\title{
Craniometric Measurements of the Male Eurasian Lynx from Turkey
}

\author{
Mustafa Orhun Dayan ${ }^{1}$, İftar Gürbüz ${ }^{2,}$, Yasin Demiraslan², Özcan Özgel ${ }^{2}$ \\ ${ }^{1}$ Selcuk University, Faculty of Veterinary Medicine, Department of Anatomy, Konya, Turkey \\ ${ }^{2}$ Mehmet Akif Ersoy University, Faculty of Veterinary Medicine, Department of Anatomy, Burdur, Turkey
}

Email address:

iftar@msn.com (İ. Gürbüz)

${ }^{*}$ Corresponding author

\section{To cite this article:}

Mustafa Orhun DAYAN, İftar Gürbüz, Yasin Demiraslan, Özcan Özgel. Craniometric Measurements of the Male Eurasian Lynx from Turkey. Animal and Veterinary Sciences. Vol. 5, No. 1, 2017, pp. 15-20. doi: 10.11648/j.avs.20170501.13

Received: January 9, 2016; Accepted: January 18, 2017; Published: February 22, 2017

\begin{abstract}
The intention of this study was to determine the morphometric features of cranium in male Eurasian lynx obtained from Turkey. In the research, craniums of totally four adult male Eurasian lynx were used. After the scalps and superficial muscles of lynx were dissected, they were boiled and macerated. Forty one measurements were taken from the cranium by the help of a digital caliper. The measurements were analysed in the SPSS (20.0 version) package software. According to the results obtained, it was determined that the maximum length of the cranium was averagely $141.37 \mathrm{~mm}$ and maximum width of the cranium was averagely $95.83 \mathrm{~mm}$ in lynx. In the study, mandible maximum length was specified as $93.45 \mathrm{~mm}$. Consequently, the osteometric measurements of the cranium and mandible in the male Eurasian lynx, which is in the threatening of extinction, were determined. It is thought that these data will be an essential data source related to the male bobcat in zooarchaeological gap in Turkey.
\end{abstract}

Keywords: Eurasian Lynx, Cranium, Morphometry

\section{Introduction}

Eurasian Lynx (Lynx lynx) is an animal species of Felidae family that lives in the forestlands of Asia and Europe [1]. In the east regions of Turkey, Eurasian Lynx (Lynx lynx dinniki) species are present which are known as the subspecies of Eurasian Lynx and are on the verge of extinction [2-4].

Morphometry is a research method enabling to investigate the form differences of the organism. It provides opportunity to mathematically express the width, length or angular measurements between two specific points [5].

Onar et al. (1997) [6] conducted some morphometric studies in the mandible of German Shepherd Dog, Onar (1999) [7] in the cranium of German Shepherd Dog, Hidaka et al. (1998) [8] in the craniums of nyctereutes procyonoides and musteline, Onar et al. (2005) [9] in the cranium of red fox, Künzel et al. (2003) [10] and Uddin et al. (2013) [11] in the cranium of cat and Monfared (2013) [12] in the cranium of Persian cat. Also, In their study
Gomeric et al. (2010) [13] indicated the findings related to skull morphometry of lynx which were obtained from Croatia. However, upon literature review, no study has been found regarding the skull morphometry of male Eurasian lynx from Turkey. Thus the purpose of this study was to specify the morphometric data of the cranium of male Eurasian Lynx which are in the east regions of Turkey in order to provide base data.

\section{Material and Method}

The craniums of 4 adult male lynxes, which were brought to Kafkas University Faculty of Veterinary Medicine Department of Pathology for autopsy on various days in order to investigate their causes of death, were used in the study. After the scalps and superficial muscles of lynx were dissected, they were boiled and macerated. 40 lengths and 5 angles were measured from the cranium by using an electronic calliper. Additionally, skull, cranial and facial indexes were also calculated by using the measurements obtained. Mean (x), standard deviation 
(SD), maximum and minimum values of the measurements and the calculations were analysed in the SPSS (20.0 version) package software.

The length measurements taken from the cranium were specified as L1: total length, L2: condylobasal length, L3: basal length, L4: basicranial axis, L5: basifacial axis, L6: neurocranium length, L7: upper neurocranium length, L8: viscerocranium length, L9: facial length, L10: lateral length of snout, L11: palatal length, L12: length of the cheektooth row, L13: length of the premolar row, L14: length of P4, L15: greatest diameter of the auditory bulla, L16: Least diameter of the auditory bulla, L17: greatest mastoid breadth, L18: greatest breadth of the occipital condyles, L19: greatest breadth of the foramen magnum, L20: height of the foramen magnum, L21: greatest neurocranium breadth, L22: zygomatic breadth, L23: frontal breadth, L24: least breadth between the orbits, L25: greatest palatal breadth, L26: breadth at the canine alveoli, L27: least breadth aboral of the supraorbital processes, L28: facial breadth between the infraorbital foramina, L29: greatest inner of the orbit, L30: greatest inner height of the orbit, L31: height of the occipital triangle, L32: total length of the mandible, L33: length from the indentation between the condyle process and angular proces-infradentale, L34: length of the condyle process and aboral border of canine alveolus-infradentale, L35: length from the indentation between the condyle process and the angular process-aboral border of canine alveolus, L36: length of the cheektooth row in mandible, L37: length of the carnassial alveolus, L38: height of the vertical ramus, L39: height of the mandible behind M1, L40: height of the mandible in front of P3 (Figure 1, Figure 2, Figure 3).

The angle measurements taken from the mandible were specified as A1: angle between the margo ventralis of corpus mandibulae and margo caudalis of ramus mandibulae, A2: angle between the tuber mandibulae of processus condylaris and the margo caudalis of ramus mandibulae, A3: angle between the ramus mandibulae and margo alveolaris of pars molaris corporis mandibulae, A4: angle of the front side of margo ventralis of corpus mandibulae, and A5: angle between two corpus mandibulae.

Driesch (1976) [14] for the length measurements, Onar et al. (1997) [6] for the angle measurements, and Onar (1999) [7] for the index calculations were taken as a reference.

Index values were calculated by using the following formulas;

a. Skull index $=\mathrm{L} 22 \times 100 / \mathrm{L} 1$

b. Cranial index $=\mathrm{L} 21 \times 100 / \mathrm{L} 6$

c. Facial index $=\mathrm{L} 22 \times 100 / \mathrm{L} 9$

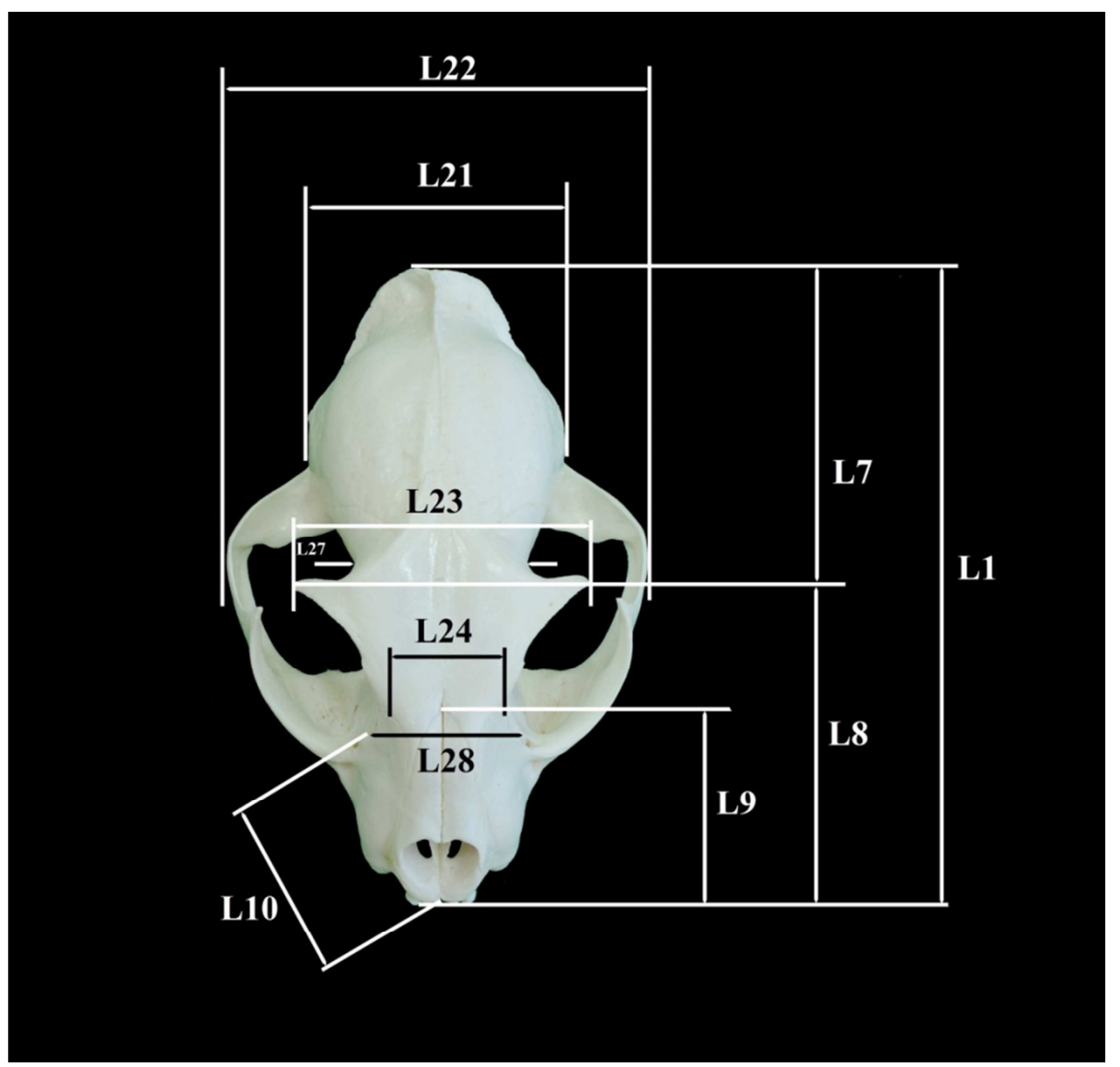

Figure 1. Dorsal view of the measurement points in the Skull of the male Eurasian lynx from Turkey.

L1: total length, L7: upper neurocranium length, L8: viscerocranium length, L9: facial length, L10: lateral length of snout, L21: greatest neurocranium breadth, L22: zygomatic breadth, L23: frontal breadth, L24: least breadth between the orbits 27: least breadth aboral of the supraorbital processes, L28: facial breadth between the infraorbital foramina. 


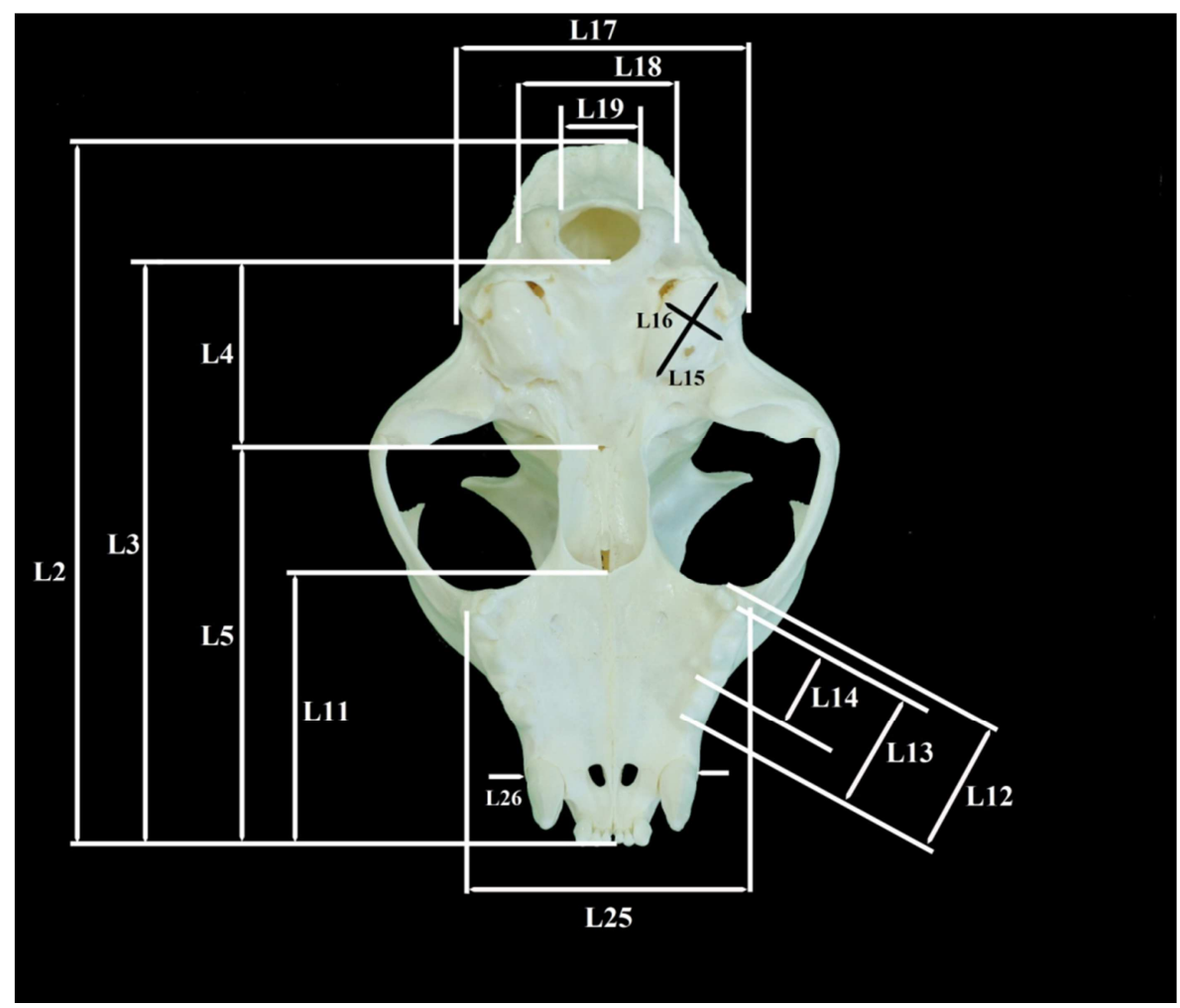

Figure 2. Basal view of the measurement points in the skull of the male Eurasian lynx from Turkey.

L2: condylobasal length, L3: basal length, L4: basicranial axis, L5: basifacial, L11: palatal length, L12: length of the cheektooth row, L13: length of the premolar row, L14: length of P4, L15: greatest diameter of the auditory bulla, L16: Least diameter of the auditory bulla, L17: greatest mastoid breadth, L18: greatest breadth of the occipital condyles, L19: greatest breadth of the foramen magnum, L25: greatest palatal breadth, L26: breadth at the canine alveoli.

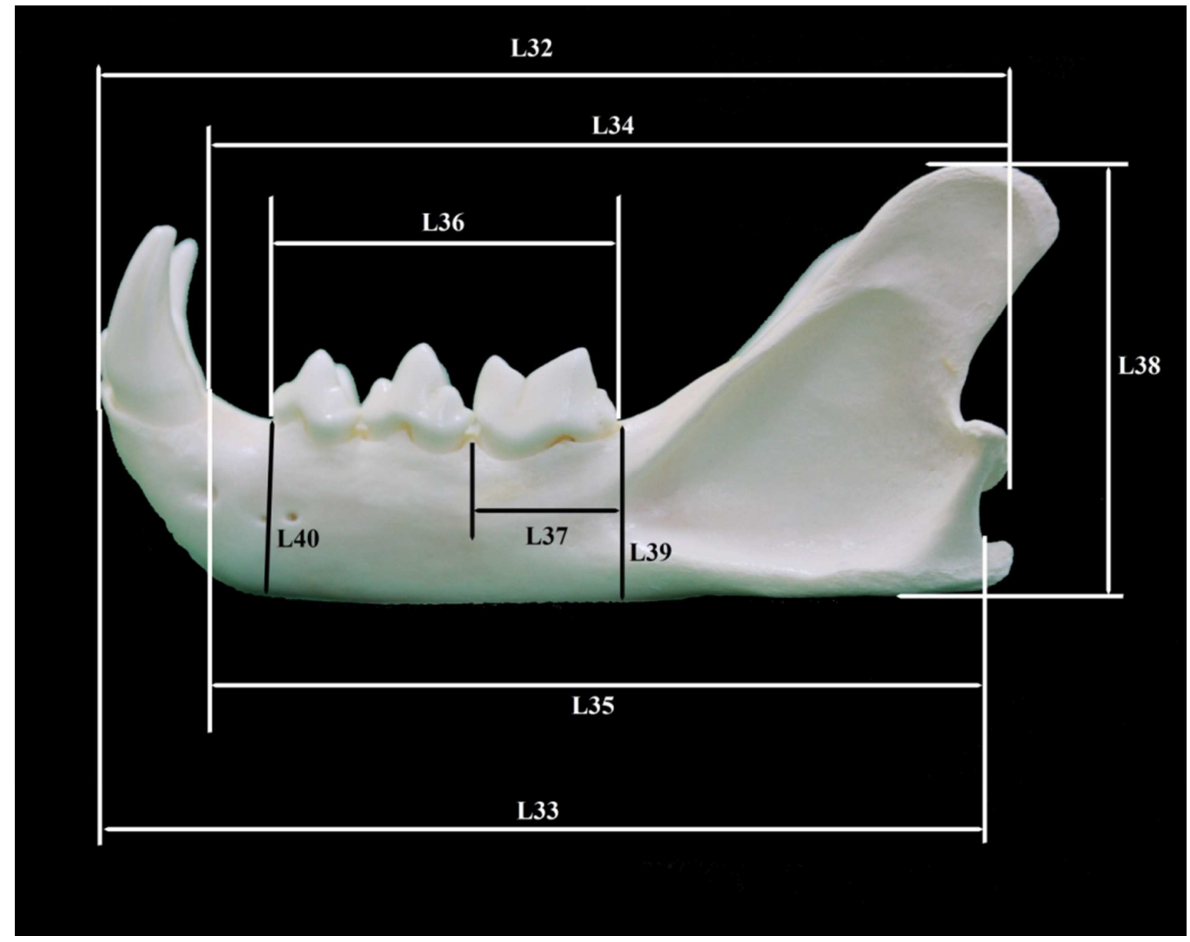

Figure 3. Lateral view of the measurement points in the mandible of the male Eurasian lynx from Turkey.

L32: total length of the mandible, L33: length from the indentation between the condyle process and angular proces-infradentale, L34: length of the condyle process and aboral border of canine alveolus-infradentale, L35: length from the indentation between the condyle process and the angular process-aboral border of canine alveolus, L36: length of the cheektooth row in mandible, L37: length of the carnassial alveolus, L38: height of the vertical ramus, L39: height of the mandible behind M1, L40: height of the mandible in front of P3 


\section{Results}

Table 1 illustrates morphometric findings of the cranium of male Eurasian Lynx.

According to the results obtained from the study; it was determined that length and width of the cranium of adult male lynx were 141.37 and $95.83 \mathrm{~mm}$ respectively, and the mandible length was $93.45 \mathrm{~mm}$. In the study, skull, cranial and facial indexes were also calculated. In the cranium of male Eurasian Lynx, skull index was found as 67.79, cranial index as 47.01, and facial index as 162.4.

Table 1. Morphometric data of the cranium of male Eurasian lynx from Turkey.

\begin{tabular}{|c|c|c|c|c|c|c|c|c|c|}
\hline Parameter & Minimum & Maximum & Mean & SD & Parameter & Minimum & Maximum & Mean & SD \\
\hline L1 & 137.83 & 147.57 & 141.37 & 5.38 & L24 & 29.46 & 30.28 & 29.81 & 0.42 \\
\hline L2 & 121.58 & 133.42 & 126.24 & 6.31 & L25 & 55.77 & 57.92 & 57.05 & 1.13 \\
\hline L3 & 111.85 & 122.12 & 115.74 & 5.57 & L26 & 33.54 & 35.46 & 34.52 & 0.96 \\
\hline L4 & 38.50 & 40.96 & 39.53 & 1.28 & L27 & 37.70 & 43.19 & 40.44 & 2.75 \\
\hline L5 & 76.06 & 82.31 & 78.39 & 3.42 & L28 & 37.68 & 39.16 & 38.64 & 0.83 \\
\hline L6 & 121.48 & 127.02 & 124.52 & 2.81 & L29 & 33.23 & 34.17 & 33.67 & 0.47 \\
\hline L7 & 76.99 & 78.75 & 78.11 & 0.98 & L30 & 36.90 & 38.27 & 37.70 & 0.72 \\
\hline L9 & 57.58 & 60.15 & 59.01 & 1.31 & L32 & 91.04 & 96.79 & 93.45 & 2.98 \\
\hline L10 & 37.26 & 39.13 & 38.02 & 0.98 & L33 & 86.40 & 94.13 & 89.13 & 4.34 \\
\hline L11 & 52.96 & 56.66 & 54.23 & 2.10 & L34 & 78.06 & 82.65 & 79.69 & 2.57 \\
\hline L12 & 30.32 & 33.96 & 31.58 & 2.07 & L35 & 74.94 & 80.60 & 76.89 & 3.21 \\
\hline L13 & 32.17 & 34.61 & 33.22 & 1.26 & L36 & 34.05 & 36.50 & 35.04 & 1.29 \\
\hline L14 & 17.94 & 19.08 & 18.40 & 0.60 & L37 & 13.76 & 14.84 & 14.23 & 0.55 \\
\hline L15 & 23.05 & 24.81 & 24.12 & 0.94 & L38 & 37.58 & 40.74 & 38.92 & 1.63 \\
\hline L17 & 57.37 & 60.72 & 59.10 & 1.68 & L40 & 16.25 & 18.50 & 17.03 & 1.27 \\
\hline L18 & 30.90 & 31.51 & 31.11 & 0.35 & A1 & 95.00 & 88.00 & 92.00 & 3.50 \\
\hline L19 & 17.30 & 17.77 & 17.54 & 0.24 & A2 & 93.00 & 87.00 & 90.00 & 3.00 \\
\hline L20 & 14.32 & 16.30 & 15.10 & 1.06 & $\mathbf{A 3}$ & 165.00 & 167.00 & 161.00 & 4.00 \\
\hline L21 & 56.84 & 59.85 & 58.54 & 1.54 & A4 & 38.00 & 32.00 & 35.00 & 3.00 \\
\hline L22 & 94.69 & 97.78 & 95.83 & 1.69 & A5 & 42.00 & 38.00 & 40.00 & 2.00 \\
\hline L23 & 59.31 & 64.43 & 62.66 & 2.90 & & & & & \\
\hline
\end{tabular}

\section{Discussion}

Eurasian Lynx is an animal species which is endemically seen in the east and north regions of Turkey and also in the forestland areas of Europe and Asia. As in numerous countries, Eurasian Lynx and its subspecies are under protection in Turkey, as well $[1,15]$. In this study, morphometric data on the cranium were obtained in terms of a single gender (male) of Eurasian Lynx which is such a rarely found and on the verge of extinction. These data are quite important in terms of zooarchaeological excavations in lynx from the Felidae family in Turkey. Morphometry is a research method that provides opportunity to determine the form differences on the organism and to make comparisons between species and even the races [5]. Actually, the reflection of morphometry and genotype to phenotype is expressed mathematically. In the study, osteometric values were obtained for the cranium of male Eurasian Lynx by using the morphometry method. The results obtained will shed light on the evaluation of species of Felidae family that will be performed in the future by using the same method.

In this study, the findings related to skull morphometry of lynx were determined. The lynx were obtained from the northeast of Turkey. In their study Gomercic et al. (2010) [13] indicated the findings related to skull morphometry of lynx which were obtained from Croatia. Besides, in the same study, Gomeric et al. (2010) [13] have complied and tabularize previously presented morphometric findings. Starting from this point of view we compared some of the data obtained with mentioned study findings. Comparing findings were summarized in table 2. According to this, it was determined that the skull measurements of the male Eurasian lynx obtained from Turkey and used as study material are similar to Spain lynx skull rather than Balkan and Eastern European lynx skull.

Künzel et al. (2003) [10] conducted morphometric studies on the cat craniums having different skull shapes. In his study, he classified the cats as round, triangular, cuneiform, and centroid. The skull of the male Eurasian lynx used in our study can be included in the class of cats having round head forms in which Persian and Birman cats are also included. Because the measured and calculated values and indexes in the study of Künzel et al. (2003) [10] are different from our study, no one-to-one comparison could be performed.

In the study conducted by Monfared (2013) [12] on the craniums of Persian cats, the cranium length, cranium width and cranial length values were determined as 10.58, 4.1, and $7.38 \mathrm{~cm}$ respectively. In our study, these values were specified as 141.37, 95.83, and $124.52 \mathrm{~mm}$, respectively. Additionally, Monfared (2013) [12] stated the skull index as 55.55 in his study. In our study, this value was found as 47.01.

In his study, Monfared (2013) [12] specified the mandible length and height as 8.3 and $3.7 \mathrm{~cm}$. In our study, these values were determined as 93.45 and $38.92 \mathrm{~mm}$. 
This study has a number of limitations. The number of animal used in the study and the presence of a single gender may be evaluated as the limitations of the study. However, the fact that Eurasian Lynx is a rare species brings the limitations of the study to a tolerable level.

Table 2. Some morphometric data of the lynx skulls obtained from different regions of the world. Values in millimeters. This table have been to modified from Gomercic et al., (2010).

\begin{tabular}{llll}
\hline Morphometric values & $\begin{array}{l}\text { Lynx (lynx lynx) from Turkey } \\
\text { (this study) }\end{array}$ & $\begin{array}{l}\text { Lynx (lynx lynx) from Crotia } \\
\text { (Gomercic et al. 2010) }\end{array}$ & $\begin{array}{l}\text { Lynx (lynx canadensis) from } \\
\text { Newfoundland (Saunders 1964) }\end{array}$ \\
\hline L1 & 137.83 & 153.2 & 129 \\
L2 & 121.58 & 142.8 & - \\
L17 & 57.37 & 67.7 & - \\
L18 & 30.90 & 32.2 & - \\
L22 & 94.69 & 111.3 & 94 \\
L32 & 91.04 & 106.8 & - \\
L40 & 16.25 & 20.3 & - \\
\hline
\end{tabular}

Table 2. Continue.

\begin{tabular}{llll}
\hline $\begin{array}{l}\text { Morphometric } \\
\text { values }\end{array}$ & $\begin{array}{l}\text { Iberian lynx (lynx pardinus) } \\
\text { (Garcia-Perea et al. 1985) }\end{array}$ & $\begin{array}{l}\text { Lynx (lynx lynx) from Norway } \\
\text { (Wiig and Andersen 1986) }\end{array}$ & $\begin{array}{l}\text { Lynx (lynx lynx) from Czech } \\
\text { (Cerveny and Koubek, 2000) }\end{array}$ \\
\hline L1 & $\begin{array}{l}\text { Lynx (lynx lynx) from the } \\
\text { Balkan (Miric 1978, 1981) }\end{array}$ \\
L2 & 133.7 & 153.1 & 153.3 \\
L17 & 121.7 & 65.4 & 139.3 \\
L18 & 58.2 & 33.9 & 65.9 \\
L22 & - & 101.3 & - \\
L32 & 95.6 & 102.3 & 107.7 \\
L40 & - & - & - \\
\hline
\end{tabular}

\section{Conclusion}

As a consequence, morphometric data regarding the cranium of an adult male Eurasian Lynx were obtained in the study. It is thought that the study will make a contribution to the literature because this is the first osteomorphometry study conducted on lynx.

\section{References}

[1] S. Aulagnier, P Haffner, A. J. Mitchell-Jones, F. Moutou, J. Zima. Mammals of Europe, North Africa and the Middle East. London, UK: A\&C Black Publishers Ltd. 2009.

[2] M. F. Price. Cooperation in the European Mountains 2: The Caucasus. Gland, Switzerland and Cambridge, UK: IUCN. 2000 .

[3] M. Von Arx, C. Breitenmoser-Wursten, F. Zimmermann, U. Breitenmoser. Status and Conservation of the Eurasian Lynx $(\operatorname{Lyn} x \operatorname{lynx})$ in Europe in 2001. Muri, Switzerland: KORA. 2004.

[4] I. Albayrak. New record of Lynx lynx (L., 1758) in Turkey (Mammalia: Carnivora). Turk J Zool. Vol. 36, 2012, pp. 814819.

[5] F. J. Rohlf, L. F. Marcus. A revolution in morphometrics. Trends Ecol E. Vol. 8, 1993, pp. 129-132.

[6] V. Onar, O. Kahvecioğlu, R. Mutuş, H. Alpak. 1997. Alman kurt köpeklerinde mandibula'nın morfometrik analizi. Turkish J Vet Anim Sci. Vol. 23, 1997, pp. 329-334.

[7] V. Onar. A morphometric study on the skull of the German Shepherd dog (alsatian). Anat Histol Embryol. Vol. 28, 1999, pp. 253-256.
[8] S. Hidaka, M. Matsumoto, H. Hiji, S. Ohsako, H. Nishinakagawa. Morphology and morphometry of skulls of raccon dogs, Nyctereutes procyonoides and badgers, Meles meles. J Vet Med Sci. Vol. 60, 1998, pp. 161-167.

[9] V. Onar, O. Belli, PR. Owen. Morphometric examination of Red Fox (Vulpes vulpes) from the Van-Yoncatepe Necropolis in Eastern Anatolia. Int J Morphol. Vol. 23, 2005, pp. 253260 .

[10] W. Künzel, S. Breit, M. Oppel. Morphometric investigations of breed-specificfeatures in feline skulls and considerations on theirfunctional implications. Anat Histol Embryol. Vol. 32, 2003, pp. 218-223.

[11] M. Uddin, M. H. R. Sarker, M. E. Hossain, M. S. Islam, M. B. Hossain, S. K. Shil. Morphometric investigation of neurocranium in domestic cat (Felis catus). Bangl J Vet Med. Vol. 11, 2013, pp. 69-73.

[12] A. L. Monfared. Anatomy of the Persian Cat's Skull and its Clinical Value During Regional Anesthesia. Global Veterinaria. Vol. 10, 2013, pp. 551-555.

[13] T. Gomercic, M. Sindicic, M. D. Gomercic, G. Guzvica, A. Frkovic, D. Pavlovic, J. Kusak, A. Galov, D. Huber. Cranial morphometry of the Eurasian lynx (lynx lynx L.) from Croatia. Veterinarski Arhiv. Vol. 80 (3), 2010, pp. 393-410.

[14] A. Von Den Driesch. A Guide to the measurement of animal bones from archaeological sites. Peabody Museum Bulletin I. Cambridge MA, Harvard University. 1976,

[15] O. E. Can. Status, Conservation and Management of Large Carnivores in Turkey. Convention on the Consevation of European Wildlife and Natural Habitats, 29 November-3 December, Strasbourg. 2004.

[16] J. K. Saunders. Physical characteristic of the Newfoundland lynx. J Mammal. Vol. 45, 1964, pp. 36-37. 
[17] R. Garcia-Perea, J. Gisbert, F. Palacios. Rewiev of the biometrical and morphological features of the skull of the Iberian lynx, Lynx pardina (Temminck, 1824). Saugetierkundl Mitt. Vol. 32, 1985, pp. 249-259.

[18] R. Wiig, T. Andersen. Sexual size dimorphism in the skull of Norwegian lynx. Acta Theriol. Vol. 31, 1986, pp. 147-155.

[19] J. Cerveny, P. Koubek. Variability of body and skull dimensions of the lynx (Lynx lynx) in the Czech Republic. Lynx (Praha). Vol. 31, 2000, pp. 5-12.

[20] D. Miric. Lynx lynx martinoi spp (carnivora, mammalia) new lynx subspecies from Balkan Peninsula (in Serbian). Glasnik Prirodnjackog Muzeja. Vol. 33, 1978, pp. 29-36.

[21] D. Miric. Balkan lynx populations (in Serbian). Srpska Akademija Nauka I Umetnosti. Beograd. 1981. 